\title{
Predicting residual service life of concrete infrastructure: a considerably controversial subject
}

\author{
Joost Gulikers* \\ *Ministry of Infrastructure and Water Management, Rijkswaterstaat-GPO, P.O. Box 2232, 3500 GE Utrecht, Netherlands
}

\begin{abstract}
There is an increasing demand from asset owners for service life prediction of existing reinforced concrete structures. This requires assessment of the current condition and modelling to allow for a prediction. This paper critically discusses a number of subjects relevant for service life prediction with respect to durability related to chloride-induced reinforcement corrosion. The subjects include the physical meaning and variability of the end-of-service-life criterion, the validity of the deterioration models, the availability, variability and reality level of input values for some model parameters, as well as some practical issues concerning site investigations. The findings are exemplified by calculation examples using both a deterministic as well as a full probabilistic approach. It is anticipated that in the future a full probabilistic approach will be adopted which makes service life predictions more prone to manipulation of input values, as literature provides a wide spectrum of values to choose from. Although a probabilistic approach seems very impressive to most asset owners it usually disguises the lack of knowledge, responsibility and liability of the consultant involved. It is concluded that asset owners will be easy prey for consultants to play a lucrative numbers game eventually providing a desirable and realistic outcome, mostly already known beforehand.
\end{abstract}

\section{Introduction}

The current stock of infrastructure contains a significant number of reinforced concrete structures reaching their originally intended design service life. In view of the economic importance of infrastructure assets in the national road and waterway network regular assessment of the current condition and prediction of the future condition is considered vital. This essential information on performance will allow timely measures to be taken on maintenance and repair, and allocate financial resources for eventual replacement.

At present the common approach is to perform visual inspections on a regular basis, which are incidentally complemented by non-destructive or minor-invasive testing. Based on these findings, maintenance activities are then planned for a time scale of 10 years. However, this approach has some drawbacks as it is a mediumterm reactive strategy and mostly focusses on individual assets, or parts of them, rather than on the network (or part of it). In order to allow for a more cost-effective preventive maintenance strategy, prediction of the longterm performance until end of original design service life and beyond, including effects due to deterioration, are therefore advocated. In view of efficient and effective long-term asset management an increasing trend can be observed that infrastructure providers and asset owners explicitly request for the residual service life of individual infrastructure assets. In practice this request will usually be accomplished by assessment of the current condition taking the observed deterioration into account and performing predictions of future condition development based on numerical modelling.

This paper will address a selection of the major pitfalls and shortcomings involved in such predictions of residual service life with respect to chloride-induced reinforcement corrosion, as this is generally considered the largest threat to long-term durability of reinforced concrete structures.

\section{Definition of end of (residual) service life}

For the quantification of the residual service life, expressed in years, a substantiated sound end-of-servicelife criterion should be established. With respect to the design of new concrete structures, according to EN 1990-1 (clause 1.5.2.8) [1], the design working life is defined as the "assumed period for which a structure or part of it is to be used for its intended use with anticipated maintenance but without major repair being necessary". In this definition a distinction is made between "maintenance" and "repair". In addition, it should be noted that maintenance is often subdivided into preventive and corrective maintenance. Repair is a typical reactive activity as it involves the elimination of physical damage, e.g. cracking and spalling of the concrete cover and loss of steel cross section in case of reinforcement corrosion. However, this definition of design working life is considered to be rather "loose" as it doesn't give any quantified information on the nature

\footnotetext{
* Corresponding author: joost.gulikers@ @rws.nl
} 
and extent of the deterioration that is considered acceptable.

In the present standards, a distinction is made between ultimate limit states and serviceability limit states, the former related to load bearing capacity and collapse, whereas the latter "corresponds to conditions beyond which specified service requirements for a structure or a structural member are no longer met" [1]. However, both ultimate and serviceability limit states do not cover aspects related to durability. Therefore, it is suggested to introduce an additional series of limit states termed either as durability, maintenance or condition limit states. Whereas codes and standards provide clear values on the minimum value of the reliability index, $\beta$, regarding ultimate and serviceability limit states which have to be demonstrated through structural calculations, for durability no $\beta$-values have been specified, but in contrast so-called deemed-to-satisfy provisions are given.

For existing concrete structures it would be evident that a similar definition as for new structures should apply, with a clear quantifiable criterion for the durability (or maintenance or condition) limit state. In view of the predictions made by modelling and the stochastic nature of the exposure conditions, concrete properties etc., it is obvious that a probabilistic approach will be adopted. This implies that the eventual result of modelling will be expressed in terms of a probability that a specified "undesirable event" will occur.

With respect to reinforcement corrosion, a number of undesirable events can be distinguished e.g. depassivation, cracking of the concrete cover and spalling of the concrete cover. For the design of new structures, depassivation of steel reinforcement resulting from either carbonation or chloride ingress is considered the most appropriate durability limit state. However, for existing concrete structures both cracking and spalling of the concrete cover may be considered as viable alternative limit states.

Assuming an agreement has been achieved on the use in practice of some durability limit state, an acceptable probability of occurrence of the corresponding "undesirable event" should be introduced. Regarding depassivation, i.e. onset of corrosion, in the literature a wide range of values for $\mathrm{P}_{\mathrm{dep}}$, considered to be acceptable, can be found. According to [2] "A probability of the onset of corrosion of $10^{-2}(\beta=2.3)$ may be more appropriate.", whereas DuraCrete [3] makes a distinction made between 3 reliability levels depending on the "Cost of mitigation of risk related to the cost of repair" with $\beta=3.72$ (low cost), $\beta=2.57$ (normal cost), and $\beta=1.28$ (high cost), corresponding to $P_{\mathrm{dep}}=0.01 \cdot 10^{-2}$, $0.5 \cdot 10^{-2}$ and $10 \cdot 10^{-2}$, respectively. It should be noted that the values proposed by DuraCrete [3] apply to "the acceptance criteria for a 50 year service life", and that "this set of acceptance criteria is only valid for analyses carried out for the specific probabilistic model used in DuraCrete". However, the first note suggests that the acceptable probability is dependent on service life (or age) of a structure (or structural member) but it remains unclear, why, and which value for a service life other than 50yr should be adopted. The second note raises serious doubt on which basis these acceptance criteria have been chosen or achieved since an acceptance criterion should be independent of the model, i.e. the mathematical expression, as well as being independent of the input values for the model parameters that have been used. According to fib [4] for depassivation, a fixed level of the reliability index $\beta=1.30\left(\mathrm{P}_{\mathrm{dep}}=10 \cdot 10^{-2}\right)$ is adopted independent of the consequence class, whereas in [5] a "probability less than approximately $10 \%$ " is considered acceptable for service life design with respect to chloride-induced corrosion. In [6] 2 reliability levels are distinguished: for exposure classes $\mathrm{XC1}, \mathrm{XC} 2, \mathrm{XC4}$, $\mathrm{XD} 1$, and XS1 $\beta=0.5$, corresponding to $\mathrm{P}_{\mathrm{dep}}=30.9 \cdot 10^{-2}$, is advocated, whereas for exposure classes $\mathrm{XC} 3, \mathrm{XS} 3$, $\mathrm{XD} 3, \mathrm{XS} 2$, and XD2 $\beta=1.5$, corresponding to $P_{\text {dep }}=6.7 \cdot 10^{-2}$, is suggested. For XS3, XD3, XS2 and $\mathrm{XD} 2$ a note is made that in case of poor accessibility and if no inspections are possible the reliability level should be increased to $\beta=1.5$.

The wide range of $\beta$-values suggested for onset of corrosion in new structures indicates that there is hardly any agreement and consistency. Moreover, barely any reasoning is provided to support the chosen $\beta$-value. In practice, it is likely that the $\beta$-values suggested for new structures will simply be copied for condition assessment of existing structures as at present in the literature no values can be found explicitly related to durability of existing concrete structures. The durability consultant will be either thrilled or confused by the availability in (reviewed) literature of such a wide range of $\beta$-values as this will provide him/her with ample possibilities to pick the most appropriate value and bear hardly any risk himself/herself. Moreover, in documents it remains largely unclear what the basis is or has been for adopting or proposing these values and what their actual physical meaning is in terms of amount of steel affected by corrosion or in other relevant physical terms, which are understandable to the asset owner. It should be noted that the asset owner will be less interested in levels of probability, but will give more consideration to risk, i.e. that account should be given to the direct physical consequences of the occurrence of an undesirable event as well as to the indirect financial consequences. With respect to reinforcement corrosion, the event of depassivation merely induces a change of the electrochemical condition of the steel. If the corrosion process following depassivation is slow, e.g. due to a high concrete resistivity or a continuous lack of oxygen to fuel the cathode reaction, a high probability of depassivation may be considered acceptable.

In practice often a $\beta$-value is preferred, as a probability value for the onset of reinforcement corrosion may provoke questions by the client on what the actual physical meaning of $\mathrm{P}_{\mathrm{dep}}$ is. However, there is a direct arithmetic relationship between the $\beta$-value and the probability, through the normal probability distribution, see Fig. 1. 


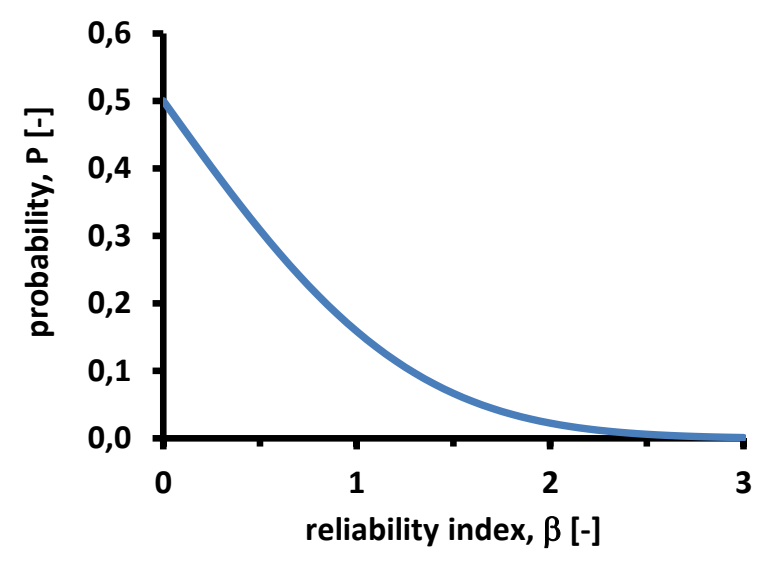

Fig. 1. Relationship between $\beta$-value and probability.

The effect of the $\beta$-value related to depassivation is illustrated in Fig. 2 regarding the (predicted) residual service life of an existing concrete structure for 3 ranges of the mean cover depth: $\mu \mathrm{c}=40,50$ and $60 \mathrm{~mm}$ (all with a standard deviation $\sigma \mathrm{c}=8 \mathrm{~mm}$ ). For a concrete structure or concrete element with a mean cover depth of $50 \mathrm{~mm}$ this implies that the (residual) service life will be in excess of $120 \mathrm{yr}$ when $\beta=0.50\left(\mathrm{P}_{\mathrm{dep}}=0.309\right)$ is adopted as the end-of-service life criterion, whereas for $\beta=1.3$ $\left(\mathrm{P}_{\mathrm{dep}}=0.097\right)$ and $\beta=1.5\left(\mathrm{P}_{\mathrm{dep}}=0.067\right)$, the service life is predicted to be $\sim 50 \mathrm{yr}$ and $\sim 40 \mathrm{yr}$, respectively.

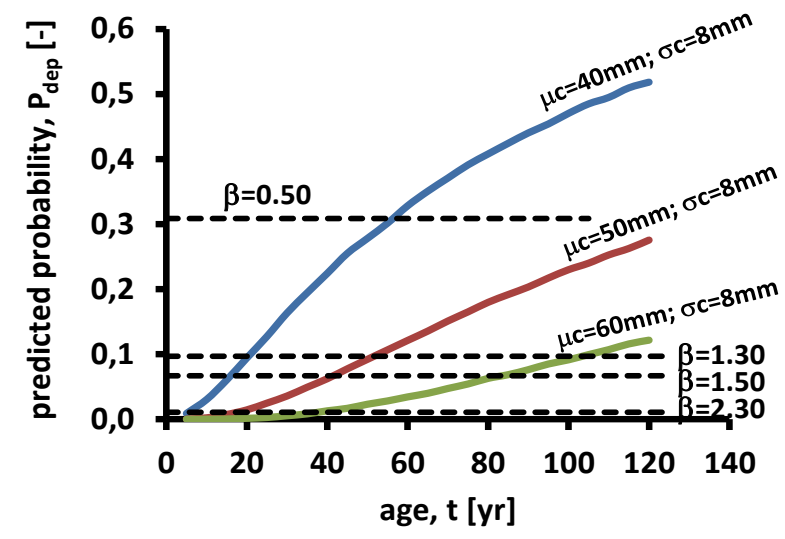

Fig. 2. Influence of the $\beta$-value on the predicted (residual) service life.

\section{Deterioration models}

In order to allow for a prediction of residual service life a suitable model for each relevant deterioration mechanism should be available. With respect to chloride-induced reinforcement corrosion a mathematical expression describing chloride transport into concrete as a function of time and depth will then be needed. In the literature, a wide variety of chloride ingress models can be found ranging from simple to highly complicated and complex taking into account a multitude of factors influencing transport of chlorides in cement-based concrete, e.g. binding, moisture content, temperature, other ionic species, time-dependent pore structure, amongst others. Most often these models are presented as either "validated" or "calibrated" models, and incidentally both qualifications are used. However, it should be appreciated that generally no further details are provided which specific requirements are fulfilled to deserve the qualification "validated" or "calibrated" and how it is demonstrated that the model proposed deserves either or both qualifications. In practice and in the literature the vagueness of these qualifications is mostly misused as they merely serve as a convincing "selling" argument.

With respect to chloride ingress in engineering practice the so-called error function solution to Fick's second law is most often used in view of its simplicity. In several case studies it has been concluded that the use of a (more) advanced model generally does not necessarily result in a better (or less worse) prediction of chloride ingress in the concrete cover. In [7] a benchmark has been performed based on measured chloride profiles from existing structures, however, the chloride profiles predicted at a later age demonstrate the significant variable outcome between the ingress models used by the respective developers.

The error function solution is given by:

$$
C(x, t)=C_{s}-\left(C_{s}-C_{i}\right) \cdot \operatorname{erf}\left(\frac{x}{2 \sqrt{D_{a} \cdot t}}\right)
$$

where $\mathrm{C}_{\mathrm{s}}=$ chloride content at the exposed concrete surface $(\% \mathrm{~m} / \mathrm{m}$ cement $) ; \mathrm{C}_{\mathrm{i}}=$ initial chloride content, $(\% \mathrm{~m} / \mathrm{m}$ cement $) ; \mathrm{x}=$ distance to the exposed concrete surface $(\mathrm{mm}) ; \mathrm{D}_{\mathrm{a}}=$ apparent chloride diffusion coefficient $\left(\mathrm{mm}^{2} / \mathrm{yr}\right) ; \mathrm{t}=$ exposure time or concrete age (t).

It should be noted that Eq. (1) represents the analytical solution to Fick's second law with 1dimensional ingress for specific boundary and initial conditions. Most often these boundary conditions are forgotten when applying the error function solution, not only in engineering practice by consultants, but surprisingly also in publications by academics and scientists. The derivation of Eq.(1) is merely valid for a semi-infinite medium and in addition it is assumed that the surface chloride content, $\mathrm{C}_{\mathrm{s}}$, remains essentially constant over time. However, in real structures these boundary conditions are often compromised, e.g. in situations with continuous exposure to chlorides where it is frequently observed that $\mathrm{C}_{\mathrm{s}}$ gradually increases over time, or at locations incidentally exposed to chlorides originating from de-icing activities during winter periods. Consequently, in most situations in practice Eq. (1) is invalid and should thus not be used. Moreover, Eq. (1) should not be applied on real concrete structures for exposure times less than $10 \mathrm{yr}$, either for prediction or for calibration purposes. However, due to the lack of knowledge by users and the poor availability of suitable alternative models on an engineering level, Eq. (1) remains by far the most popular model for chloride ingress for application in both practice and in experimental research in the laboratory.

Based on field experience with chloride profiles measured on concrete cores drilled from existing structures, it is concluded that the apparent diffusion 
coefficient, $\mathrm{D}_{\mathrm{a}}$, is time-dependent according to an empirical power law relationship:

$$
D_{a}(t)=D_{a}\left(t_{r e f}\right) \cdot\left(\frac{t_{r e f}}{t}\right)^{n}
$$

where $\mathrm{D}_{\mathrm{a}}(\mathrm{t})=$ apparent chloride diffusion coefficient $\left(\mathrm{mm}^{2} / \mathrm{yr}\right)$ at age $\mathrm{t} ; \mathrm{D}_{\mathrm{a}}\left(\mathrm{t}_{\text {ref }}\right)=$ apparent chloride diffusion coefficient $\left(\mathrm{mm}^{2} / \mathrm{yr}\right)$ at reference age $\mathrm{t} ; \mathrm{n}=$ ageing factor $(-)$

However, it is widely known that this modified version employing a time-dependent chloride diffusion coefficient according to Eq. (2) does not satisfy the underlying differential equation, i.e. Fick's second law of diffusion, any more. Consequently, numerical models using consecutive time steps with the differential equation as the basis will result in a completely different outcome than the outcome obtained by the combination of Eq. (1) and Eq. (2). Therefore, it is generally strongly recommended not to apply software with the differential equation as the basis for use in practice by engineers.

A sensitivity analysis on the influence of individual model parameters has clearly demonstrated the dramatic impact of the ageing factor, $\mathrm{n}$, on the chloride ingress rate and thus on time to depassivation of the embedded reinforcing steel. Therefore, behind the scenes in the absence of clients, the ageing factor $\mathrm{n}$ is frequently referred to as the "manipulation factor". Fig. 3 shows the relative influence of the ageing factor, $n$, on the predicted age at depassivation of the reinforcing steel for an existing concrete structure based on inspection results obtained at an age $t_{\text {ref }}\left(=t_{\text {insp }}\right)=20$ yr with $D_{a}\left(t_{\text {ref }}\right)=$ $15 \mathrm{~mm}^{2} / \mathrm{yr}$ (equal to $0.475 \cdot 10^{-12} \mathrm{~m}^{2} / \mathrm{s}$ ), $\mathrm{C}_{\mathrm{s}}=3.0 \%, \mathrm{C}_{\mathrm{i}}=0.1 \%$, and a critical chloride content, $\mathrm{C}_{\text {crit }}=0.5 \%$, for 3 different cover depths, $\mathrm{c}=40,45$ and $50 \mathrm{~mm}$, according to a deterministic calculation.

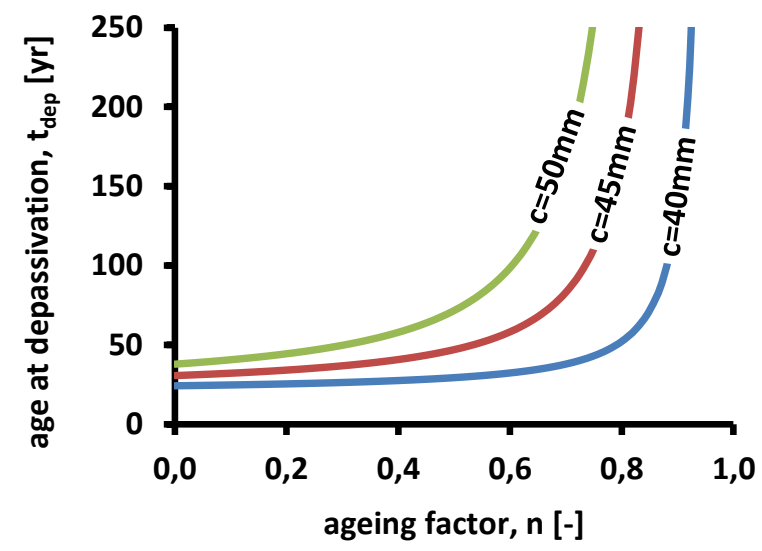

Fig. 3. Influence of the ageing factor, n, on the predicted age at depassivation, $t_{\text {dep }}$.

In most publications as well as in most calculations it is assumed that the ageing factor lies between $0.0 \leq \mathrm{n} \leq 1.0$ $[3,4]$. An ageing factor $n=0$ implies that the chloride transport properties as expressed by $\mathrm{D}_{\mathrm{a}}$ will remain constant over time, e.g. $\mathrm{D}_{\mathrm{a}}(\mathrm{t})=\mathrm{D}_{\mathrm{a}}\left(\mathrm{t}_{\mathrm{ref}}\right)$. Using a value $\mathrm{n}<0.0$ implies that $\mathrm{D}_{\mathrm{a}}$ will increase over time and thus will demonstrate gradually less resistance against chloride ingress whereas for $\mathrm{n}>0$ this resistance will increase over time. At first glance such a time-dependent decrease of $\mathrm{D}_{\mathrm{a}}$ seems reasonable considering the refinement of the pore structure and decrease of the porosity as a result of ongoing hydration of the binder, in combination with a decrease of the moisture content due to a gradual drying out of the concrete at greater depths. However, this reasoning becomes questionable for concretes having an age of more than $50 \mathrm{yr}$ as hydration will have come to an end, resulting in a static pore structure, whereas the moisture distribution in the cover zone may have come to a dynamic equilibrium with the exposure environment. Moreover, it could also be reasoned that, after some point in time, $\mathrm{D}_{\mathrm{a}}$ may increase as a result of the occurrence of microcracking, e.g. in the tensile zone, or due to a change in the exposure conditions, e.g. through the occurrence of leakage. However, in most predictions of chloride ingress over time it is assumed that Eq. (2) is valid with a constant nvalue until infinity.

For $\mathrm{n}=1.0$ the chloride profile will not change over time, and this is explained by a phenomenon termed "pore blocking" [8]. For $\mathrm{n}>1.0$ the resistance to chloride ingress will increase over time at a rate that chlorides will withdraw and the chloride content will decrease. However, it is highly unrealistic that such a phenomena will occur in practice. Fig. 4 shows the predicted change over time of the chloride content at a fixed depth $\mathrm{x}=$ $40 \mathrm{~mm}$ for $\mathrm{n}=-0.25, \mathrm{n}=+0.00, \mathrm{n}=+0.50, \mathrm{n}=+1.0$, and $\mathrm{n}=+1.25$. The input used is based on a measured chloride profile at $\mathrm{t}_{\text {ref }}\left(\right.$ or $\left.\mathrm{t}_{\mathrm{insp}}\right)=20 \mathrm{yr}$ using $\mathrm{C}_{\mathrm{s}}=3.0 \%, \mathrm{C}_{\mathrm{i}}=0.1 \%$, and $\mathrm{D}_{\mathrm{a}}\left(\mathrm{t}_{\mathrm{ref}}\right)=15 \mathrm{~mm}^{2} / \mathrm{yr}$ (this input is identical to that used for the previous example).

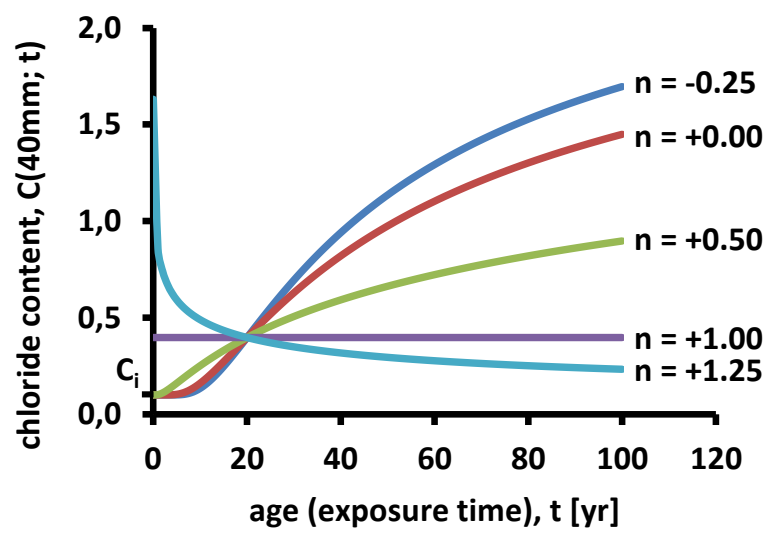

Fig. 4. Influence of the ageing factor, $\mathrm{n}$, on the predicted development over time of the chloride content at a depth $\mathrm{x}=40 \mathrm{~mm}$.

Although values for the ageing factor $n>1.0$ are unrealistic, such values are frequently reported for binders with high amounts of supplementary cementitious materials, in particular blast furnace slag and fly ash [9, 10]. However, such findings may then raise considerable doubt either on the quality of the investigations, the validity of the empirical relationship or on the physical interpretation of ageing effects.

As a case study that has actually occurred in practice, the values reported in [10], $0.90<\mathrm{n}<1.05$ derived with results obtained from chloride migration tests, were 
proposed by a contractor in a project to demonstrate the superior resistance to chloride ingress of the concrete cover. The contractor expressed a clear preference for a numerical proof although the joint between precast concrete elements of a bridge deck showed serious leakage and shallow cover depths. For values $n>1.0$ chloride contents were calculated merely at the depth of the reinforcing steel, $\mathrm{x}=30 \mathrm{~mm}$, at $\mathrm{t}=\mathrm{t}_{\text {design }}=100 \mathrm{yr}$, however this will surely not reveal that the predicted chloride contents will actually decrease over time, see Fig. 4. When confronted with this predicted highly unrealistic decrease of the chloride content over time, the contractor had not a word to say.

In the literature, a wide range of values for the ageing exponent, $n$, are reported depending on the type of cement and exposure conditions (humidity). However, generally no background is provided on the number and quality of the data that is available, nor on the type and age of the structures or on the local exposure conditions. It should be noted that the magnitude of the ageing factor cannot be measured but is derived by curve fitting of values for $\mathrm{D}_{\mathrm{a}}$ obtained for a similar concrete composition and exposure conditions during a long period of time, preferably more than 50 years. In practice only a limited amount of data is often available coming from different structures and sources having apparently similar concrete composition (cement type) and exposed to apparently similar environmental conditions.

In practice, chloride ingress generally will have sufficiently advanced only after more than 15 years of frequent exposure. Consequently, there is a considerable lack of data on $\mathrm{D}_{\mathrm{a}}(\mathrm{t})$ covering the time period $0.1 \mathrm{yr}<\mathrm{t}<$ $15 y r$. In [4] and [11] this is solved by introducing values obtained from laboratory tests, i.e. the chloride migration coefficient, $\mathrm{D}_{\mathrm{RCM}}$, as a substitute. This results in a mix of values for $D_{R C M}(t)$ and $D_{a}(t)$ to quantify the ageing factor, $\mathrm{n}$, by regression analysis, however it is wellknown that the migration coefficient, $\mathrm{D}_{\mathrm{RCM}}(\mathrm{t})$ demonstrates a significantly different time-dependent behaviour than $\mathrm{D}_{\mathrm{a}}(\mathrm{t})$. Consequently, the magnitude of the ageing factor thus derived will generally be considerably less than the actual $n$-value based on $D_{a}$-values only, in particular for concretes made with binders containing SCM's [12].

\section{Probabilistic approach}

As there is significant uncertainty associated with most model parameters, in particular the ageing factor $\mathrm{n}$ and the critical chloride content, $\mathrm{C}_{\text {crit }}$, it is considered more appropriate to use a probabilistic approach [13] This implies that all model parameters are subject to a statistical description, which are then treated as statistically independent random variables.

In the error-function solution to Fick's second law 5 stochastic parameters can be identified, i.c. the surface chloride content, $\mathrm{C}_{\mathrm{s}}$, the initial chloride content, $\mathrm{C}_{\mathrm{i}}$, the reference apparent diffusion coefficient, $\mathrm{D}_{\mathrm{a}}\left(\mathrm{t}_{\mathrm{ref}}\right)$, and the ageing factor, $n$. The reference concrete age, $t_{\text {ref, }}$ and the age for the prediction, $t$, are the only deterministic variables, having a predefined value. With respect to depassivation of the steel reinforcement, the thickness of the concrete cover, c, and the critical chloride content, $\mathrm{C}_{\text {crit }}$, are also considered as stochastic variables. In principle, the statistical distribution adopted for each parameter, is reflected in a mean value, a standard deviation and a type of probability distribution, e.g. a lognormal distribution.

Frequently, there is a lack of data on a specific model parameter and in the absence of any other information it is common practice to disguise this lack of statistical data by giving the designation "based on expert opinion". In addition, due to this lack of enough data, a normal probability distribution is frequently chosen as this is the most obvious one. However, for certain parameters the pitfall is that a normal distribution may result in negative values, in particular when, probably based on arbitrary grounds, a large standard deviation is chosen. An illustrative example of the consequences is provided in [14], see Fig. 5, regarding the surface chloride content, $\mathrm{C}_{\mathrm{s}}$. For each exposure environment distinguished for marine structures, $\mathrm{C}_{\mathrm{s}}$ is characterised by a mean value, $\mu$, and a coefficient of variation, $\mathrm{COV}$, with $\sigma=\mathrm{COV} \cdot \mu$. The values adopted for $\mathrm{COV}$ are 0.80 , $0.71,0.50$, and 1.33 , which correspond to a probability that $\mathrm{C}_{\mathrm{s}}<0$ of $\mathrm{P}=0.106,0.081,0.023$, and 0.227 , respectively. It is obvious that negative chloride contents do not exist, and that a lognormal or a left truncated normal distribution would have been a more realistic choice to statistically describe $\mathrm{C}_{\mathrm{s}}$. On the other hand, the surface chloride content, $\mathrm{C}_{\mathrm{s}}$, has a relatively minor impact on the outcome, thus this unrealistic choice will probably not lead to significant changes of the outcome.

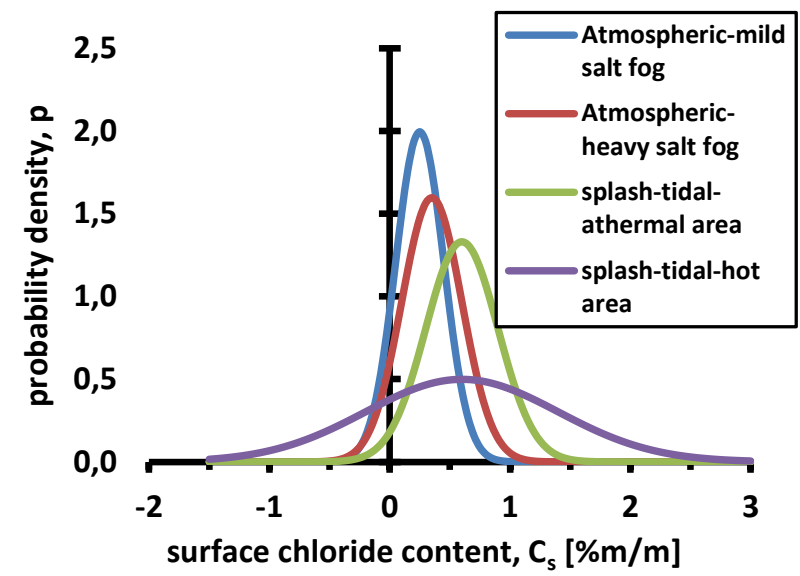

Fig. 5. Example of the use of a normal probability distribution for the surface chloride content. $\mathrm{C}_{\mathrm{s}}$, with a large standard deviation, resulting in negative values.

Regarding the critical chloride content, $\mathrm{C}_{\text {crit }}$, literature provides a wide variety of input values [3, 4, 15, 16]. Some authors assume that $\mathrm{C}_{\text {crit }}$ is independent of exposure conditions or type of binder [4], whereas others indicate a strong dependency, especially from the exposure environment [3,15]. Of particular interest for discussion is the detailed statistical distribution of $\mathrm{C}_{\text {crit }}$ provided in [15], as this characterization is based on results of long-term experiments in a natural exposure environment. For the atmospheric zone, a lognormal 
distribution was adopted whereas for both the splash as well as the submerged zone a beta-distribution was chosen, characterised by both a lower and an upper boundary. The probability density of $\mathrm{C}_{\text {crit }}$ for each environmental zone is presented in Fig. 6, whereas the corresponding (cumulative) probability is illustrated in Fig. 7.

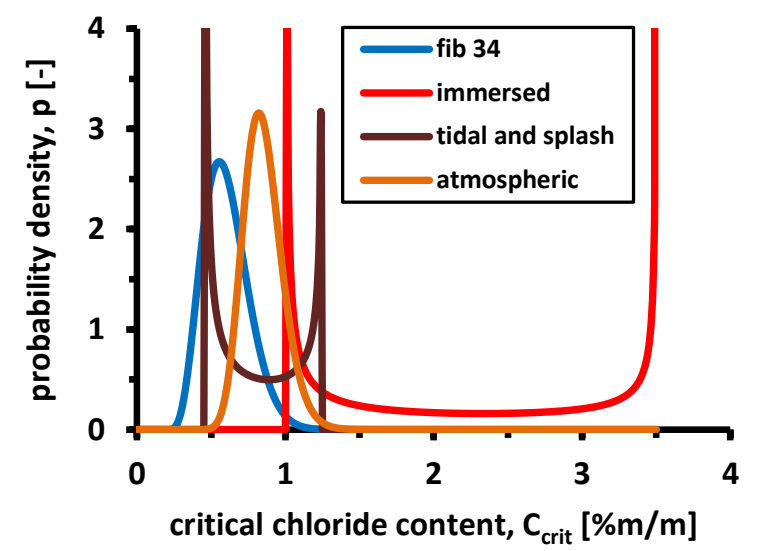

Fig. 6. Probability density distributions of $\mathrm{C}_{\text {crit }}$ according to [4] and [15]

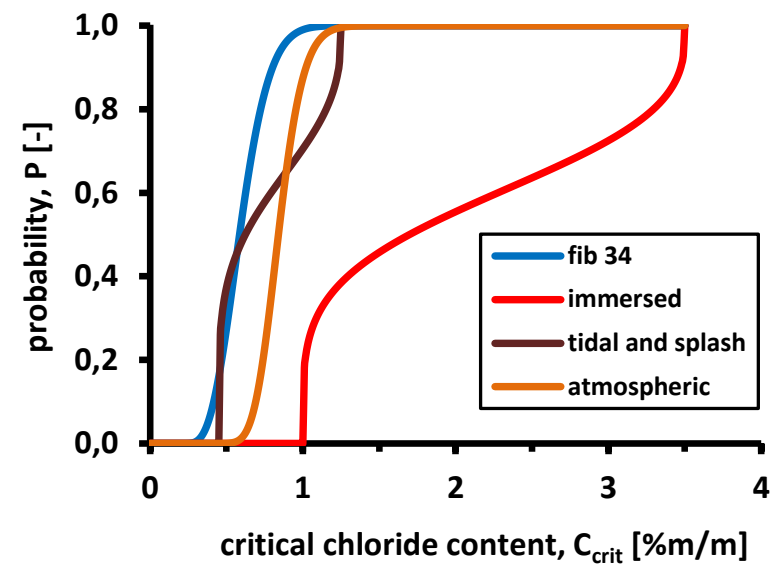

Fig. 7. Probability distributions of $\mathrm{C}_{\text {crit }}$ according to [4] and [15]

For both $\mathrm{C}_{\text {crit }}$ according to [4] and $\mathrm{C}_{\text {crit }}$ for the atmospheric zone in [15] the probability density distribution shows a familiar appearance with a peak value around the mean value. In contrast, according to [15], for both the immersed as well as the combined tidal and splash zone, the probability density distribution shows extreme density peaks at the lower and the upper boundary, whereas in the region between the lower and upper boundary, a nearly constant low probability density exists. Both probability density curves are also shown in [15], however no explanation is given, nor a discussion provided on their realistic nature. Without doubt such curves raise considerable doubt on their validity for use in practice on real concrete structures.

\section{Practice-related issues}

For assessment of existing reinforced concrete structures with respect to chloride-induced corrosion, it is common practice to drill a number of concrete cores from selected parts of the structure. Thereupon, the chloride profiles are composed giving the chloride content as a function of depth. For the assessment of the present condition, the chloride content measured at the level of the reinforcing bars is compared to the assumed critical chloride content. For prediction of the development of the condition over time, the measured chloride profiles are subjected to regression analysis using Eq. (1). This fitting procedure eventually results in values for the apparent chloride diffusion coefficient, $\mathrm{D}_{\mathrm{a}}\left(\mathrm{t}_{\mathrm{insp}}\right)$, and the surface chloride content, $\mathrm{C}_{\mathrm{s}}$. Thereupon, by assumption, engineering judgement or expert opinion suitable values for the ageing factor, $\mathrm{n}$, and the critical chloride content, $\mathrm{C}_{\text {crit }}$, are introduced. Then, either a deterministic or a probabilistic approach is adopted to predict future chloride ingress and the time to depassivation of the reinforcing steel. Although this procedure seems straightforward, there are some critical issues involved.

Most often, measured chloride profiles are characterised by a limited number of relevant chloride contents: sometimes only 2 valid points are available, especially for structures, structural elements or parts of the structure with exposure times less than 15-20 years. This is due to a combination of shallow chloride penetration depths, the use of depth increments of $10 \mathrm{~mm}$ or more, and the common neglect of the chloride content of the near-surface layer. Generally, chloride measurements executed by scientific institutes provide results within $10 \%$ of the real chloride content present, however, experience in practice with commercial laboratories indicate that a difference of more than $20 \%$ is more common. Without doubt, this inaccuracy will be reflected in the values obtained for $\mathrm{D}_{\mathrm{a}}\left(\mathrm{t}_{\text {insp }}\right)$ and $\mathrm{C}_{\mathrm{s}}\left(\mathrm{t}_{\text {insp }}\right)$, and eventually this will affect the validity of the predictions.

It is common practice that the chloride content of the near-surface layer is discarded as it does not fit in the chloride profile obtained by Eq. (1). This implies that in fact the surface chloride content, $\mathrm{C}_{\mathrm{s}}$, physically does not exist and instead its notional value is obtained by extrapolation of chloride contents measured at depths $>$ $10 \mathrm{~mm}$ to the exposed concrete surface, i.e. to $\mathrm{x}=0$. In practice, frequently chloride profiles are measured for which the second point also deviates from the chloride profile according to Eq. (1). In these cases either both the first and the second point are discarded, or merely the first point. Figure 8 exemplifies such a situation by 2 chloride profiles measured at the windward side of a box girder bridge exposed to an atmospheric marine environment. The initial rise in chloride going in is well known due to the effect of carbonation releasing bound chloride pushing a ramp of chloride ahead of the carbonation front. In addition, frequent exposure to rain can also influence the chloride profile in the near-surface layer. 


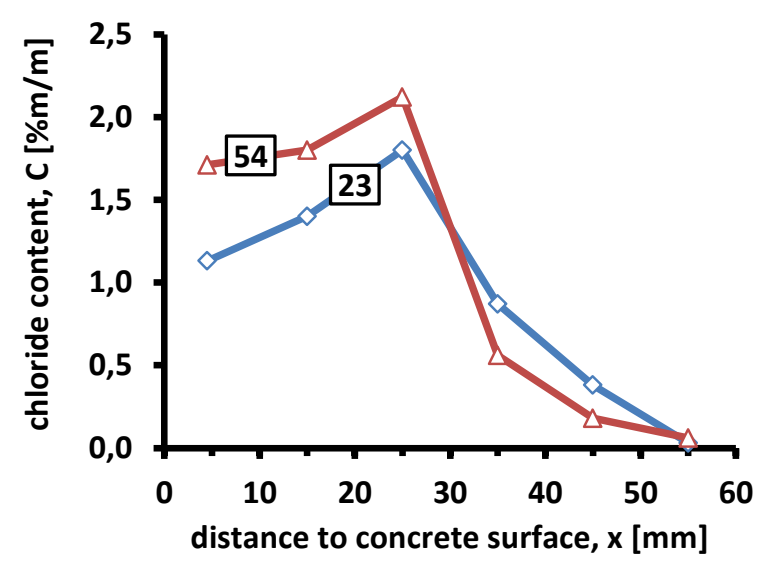

Fig. 8. Chloride profiles with contents measured at 5 and $15 \mathrm{~mm}$ not complying with Eq.(1) (depth increments of 10mm).

Consequently, the results of the regression analysis regarding $\mathrm{D}_{\mathrm{a}}\left(\mathrm{t}_{\text {insp }}\right)$ and $\mathrm{C}_{\mathrm{s}}$ will be seriously affected by the points chosen. For chloride profile 54, the use of points 2-6 will result in $\mathrm{C}_{\mathrm{s}}=3.53 \%(\mathrm{~m} / \mathrm{m}$ cement) together with $\mathrm{D}_{\mathrm{a}}\left(\mathrm{t}_{\text {insp }}\right)=13.1 \mathrm{~mm}^{2} / \mathrm{yr}$, whereas in case points 3-6 would have been used, regression analysis would have resulted into $\mathrm{C}_{\mathrm{s}}=17.3 \%$ and $\mathrm{D}_{\mathrm{a}}\left(\mathrm{t}_{\text {insp }}\right)$ $=4.0 \mathrm{~mm}^{2} / \mathrm{yr}$, see Fig. 9. This significant difference in results obtained by regression analysis indicates that serious caution should be exercised in discarding measured chloride contents. Sometimes complete chloride profiles are discarded as too many points do not match with Eq. (1). However, it should be noted that also such "non-matching", undesirable profiles represent the facts and simply considering these profiles as outliers will be far too easy.

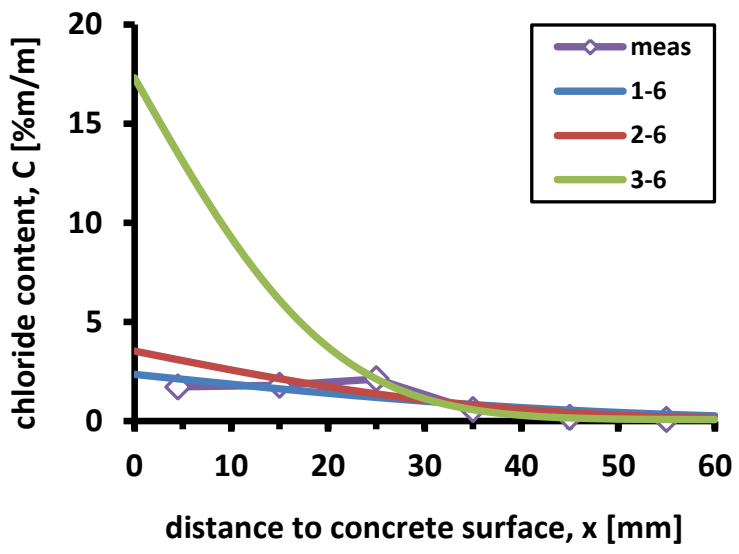

Fig. 9. Measured chloride profile no. 54 with corresponding chloride profiles fitted according to Eq. (1).

An alternative is to use smaller depth increments, e.g. $5 \mathrm{~mm}$, which provide more data points characterizing a profile and allows for a better identification of the depth at which depth the actual peak in the chloride profile occurs. However, this may have serious cost implications. In addition, the amount of material available for the chloride analysis will be less and may be such that it will impair the reliability of the quantification of both the amount of chloride and cement present in the concrete sample.
An additional serious issue regarding costs is the number of concrete cores required to obtain a reliable representative picture of chloride ingress over the concrete structure or part of it, e.g. a support. It should be noted that each concrete core retrieved from the structure corresponds to a hole, which should be repaired.

Spatial variability and accessibility are important aspects to be considered in choosing the number of cores and the appropriate locations for coring. Even for situations with apparently uniform exposure conditions and quality of the concrete cover, the differences between chloride profiles obtained from adjacent spots may be significant. Moreover, some locations in a structure, although known to be exposed to a more aggressive local environment than others, may not be easily accessible. Another area, at short distance from the heavily exposed area, may be easily accessible, but the chloride load in this alternative area may be far less, e.g. in situations with local leakage of bridge joints. Consequently, such chloride profiles will provide a far too optimistic picture on chloride ingress. In practice, chloride profiles are deliberately taken from areas in structures experiencing the most aggressive exposure conditions. However, these areas may be relatively small compared to the total surface area of the complete structure. It is obvious that a condition assessment and service life prediction of a concrete structure merely based on the results obtained from such areas will provide a far too pessimistic view of the overall state of the complete structure.

\section{Concluding remarks}

Prediction of residual service life of existing concrete structures is subject to serious doubt, not only with regard to the procedure adopted, the chloride profiling, the appropriateness of the deterioration models employed, the input values chosen, and the end-ofservice-life criterion, but also on the usefulness of the outcome for the asset owner regarding maintenance and repair.

At present, a trend is observed towards the use of probabilistic approaches, explicitly taking into account the uncertainties in the model as well as the uncertainties in the quantification of the model parameters. However, there is a significant lack of quality data on the actual exposure conditions to which a concrete structure is subjected and its response, in particular in the long term. This implies that the statistical characterization of most model parameters is often assumed, invented or based on "expert opinion", however without providing any reasoning or evidence.

In practice there is a serious risk that statistical characterizations of model parameters published in papers authored by scientists will simply be copied by engineers, with a reference to the source, however without expressing any caution. It is obvious that adopting such a copy behaviour will have serious consequences for the reliability of residual service life predictions. As the majority of asset owners has hardly 
any feeling for modelling of deterioration processes, probabilistic approaches or reliability indices, he/she will be almost completely handed over to the professional integrity, expertise, objectivity, personal preference and randomness of the consultant, however without any control. Consequently, asset owners are an easy prey for consultants to play a lucrative numbers game eventually providing a desirable and realistic outcome, known beforehand.

\section{References}

1. EN1990, Eurocode - Basis for structural design (2002)

2. P. Bamforth, Double standards in design, Concrete, pp. 33-35. (2009)

3. DuraCrete, General guidelines for durability design and redesign, Final Technical Report, Document BE95-1347/R17, May 2000

4. fib Model Code for Service Life Design, bulletin 34, February 2006

5. CUR, Durability of structural concrete regarding chloride-induced reinforcement corrosion, Guideline for the formulation of performance requirements-Background report (in Dutch) (2009)

6. C. Gehlen, P. Schiessl, A. Schiessl-Pecka, Position paper of DAfStB on implementation of the concept of performance-based design approaches considering DIN EN 206-1, Annex J. Beton- und Stahlbetonbau, 103, Heft 12, pp. 837-839 (in German) (2008)

7. E.A.B. Koenders, Modelling of chloride ingress in concrete based on benchmarking field results, ICCRRR 2018, Cape Town

8. M. Maage, S. Helland, E. Poulsen, Ø. Vennesland, J.E. Carlsen, Service life prediction of existing concrete structures exposed to marine environment, ACI Materials Journal, November-December 1996, pp. 1-8

9. M.D.A. Thomas, P.B. Bamforth, Modelling chloride diffusion in concrete - Effect of fly ash and slag, Cement and Concrete Research 29 (1999) pp. 487495.

10. G.J.L. van der Wegen, M.M.R. Boutz, A.J. Sarabèr, R.J. van Eijck, Ageing coefficient of fly ash concrete and its impact on durability, Proc. of the $1^{\text {st }}$ Int. Conf. on Ageing of Materials \& Structures, Delft, 26-28 May 2014, pp. 171-177

11. CUR, Durability of marine concrete structures, Publication 215 (in Dutch) (2005)

12. J.Gulikers, A critical review of mathematical modelling of chloride ingress into concrete and the derivation of input data, in Performance based Evaluation and Indicators for Concrete Durability, Proceedings of the International RILEM Workshop, Proceedings PRO 47, Madrid, 2006, pp. 165-175

13. D.V. Val, P.A. Trapper, Probabilistic evaluation of initiation time of chloride-induced corrosion,
Reliability Engineering \& System Safety, 93 (2008), pp. 364-372

14. X.P. Zhong, J. Zhu, C.B. Yuan, W.L. Jin, J. Xia Durability design based on serviceability stage for corroded reinforced concrete structures, Sixth International Conference on Durability of Concrete Structures, 18-20 July 2018, paper number DDS01, pp. 859-865

15. K. Li, Q. Li, X. Zhou, Z. Fang, Durability design of the Hong Kong-Zhuhai-Macau sea-link project: Principle and procedure, Journal of Bridge Engineering, 2015, 20(11), pp. 1-11

16. M. Thomas, Chloride thresholds in marine concrete, Cement and Concrete Research, Vol. 14, No. 4, 1996, pp. 513-519 